\title{
JOSÉ N. ROVIROSA: SUS ESCRITOS CIENTÍFICOS SOBRE RECURSOS NATURALES, 1880-1900 \\ Rodrigo A. Vega*
}

RESUMEN: En el gobierno de Porfirio Díaz se fomentaron los estudios naturalistas y geográficos con el objetivo de inventariar y estudiar los recursos naturales de las regiones mexicanas para aprovecharlos económicamente. En el caso del Estado de Tabasco, el ingeniero José Narciso Rovirosa publicó números estudios que versan sobre las maneras de explotar la flora y fauna local. Esto trajo como consecuencia la rápida transformación de los ecosistemas tabasqueños en el último tercio del siglo XIX.

\section{শ্ৰ)}

ABSTRACT: During Porifio Diaz's government, naturalistic and geographic studies of Mexican regions were fostered in order to categorize and study their natural resources for economic benefit. In particular, engineer José Narciso Rovirosa, published various studies detailing the best ways of utilizing the local flora and fauna in the Tabasco state. Consequently, the latter led to the quick transformation of its ecosystems in the third quarter of the nineteenth century.

PAlABRAS Clave: Tabasco, Historia natural, Geografía, Medio ambiente, Porfiriato. KEY WORDS: Tabasco, Natural History, Geography, Environment, Porfiriato.

RECEPCIÓN: 19 de septiembre de 2012.

APROBACIÓN: 24 de enero de 2013.

* Colegio de Historia, Facultad de Filosofía y Letras, UnAM. 
CITAM Derechos Reservados.

La reproducción total o parcial de este artículo se podrá hacer si el ITAM otorga la autorización previamente por escrito. 


\section{JOSÉ N. ROVIROSA: SUS ESCRITOS CIENTÍFICOS SOBRE RECURSOS NATURALES, 1880-1900*}

\section{Entre las diversas definiciones que} se han propuesto en las últimas décadas para la Historia ambiental resalta la de Donald Worster, para quien el objetivo es la comprensión de las formas "en que los seres humanos han sido afectados por su ambiente natural a lo largo del tiempo y, a la inversa, de la manera en que han afectado al ambiente, y con qué resultados". ${ }^{1}$ De forma similar, Claudia Leal enfatiza el aspecto de los recursos naturales en la historia y la necesidad de emprender investigaciones que exploren los intereses sociales que han mediado su uso "y las disputas que allí se han originado, así como también el papel que han tenido el Estado y las políticas públicas en transformar el ambiente al regular el acceso a los recursos".2

En un sentido similar, Stefanía Gallini señala que la Historia ambiental debe centrarse en "cómo los ecosistemas latinoamericanos han sido transformados profundamente por las fuerzas de la economía mundial durante los siglos XIX y XX". ${ }^{3}$ Asimismo, para ambas centurias resulta

* Esta investigación forma parte del proyecto PAPIIT (IN 303810): "Naturaleza y territorio en la ciencia mexicana (1768-1914)", Instituto de Geografía-UNAM, responsable Dra. Luz Fernanda Azuela.

${ }^{1}$ Donald Worster, The ends of the Earth: Perspectives on modern environmental history, 1988, Cambridge, Cambridge University Press, p. 291.

${ }^{2}$ Claudia Leal, "Presentación del dossier sobre historia ambiental latinoamericana", Historia Crítica, 2005, núm. 30, p. 6.

${ }^{3}$ Stefania Gallini, "Historia, ambiente, política: el camino de la historia ambiental en América Latina”, Nómadas, 2009, núm. 30, p. 94. 
necesario profundizar en la lectura ambiental de la historia del "progreso" científico y construir historias en donde los recursos naturales sean los protagonistas, ya que "los bienes de exportación primarios tuvieron su propia historia y estamos apenas entendiéndola". ${ }^{4}$

De entre la gama de fuentes que tradicionalmente han sido empleadas por la Historia de la ciencia resultan importantes para la Historia ambiental aquellas que "ponen mayor o menor atención a las transformaciones del paisaje o a las concepciones de la naturaleza". ${ }^{5}$ De esta manera, para la presente investigación la obra científica de los naturalistas mexicanos del siglo XIX se convierte en fuente para los estudios ambientales, pues en este tipo de escritos se encuentra la visión que éstos tuvieron acerca de los recursos naturales del país. En efecto, la relevancia de adentrarse en la comprensión histórica de la producción científica mexicana, en este caso un autor, se asienta en las posibilidades de examinar la obra intelectual que da cuenta de los procesos ambientales suscitados en una región y tiempo determinados. ${ }^{6}$

En esta investigación se abordará el caso de la obra naturalista del ingeniero tabasqueño José Narciso Rovirosa (1849-1901) como fuente para la Historia ambiental de su terruño, entre 1880 y 1900, lo que permitirá advertir los vínculos existentes entre las historias de las ciencias y las ambientales de México. La región a tratar es el estado de Tabasco, ya que la mayoría de los estudios de Rovirosa se circunscribieron a este territorio político. Las fuentes consultadas fueron los diversos escritos científicos que versan sobre Geografía e Historia natural, cuyo objetivo fue el aprovechamiento de los recursos naturales para el impulsar el progreso material de la entidad.

${ }^{4}$ Ibid., p. 97.

${ }^{5}$ Leal, op. cit., p. 7.

${ }^{6}$ En los últimos años se han iniciado estudios que revelan cómo los científicos mexicanos llevaron a cabo investigaciones sobre la viabilidad de explotar los recursos naturales. Véase: Luz Fernanda Azuela, "Los estudios de las aguas minerales en México en el siglo XIX y su impacto sobre la ciencia y la sociedad", en Patricia Aceves (coord.), Farmacia, Historia Natural y Química Intercontinentales, 1996, México, UAM-X, pp. 241-56; Dení Trejo, “Antonio del Castillo y José María Esteva. Sus estudios sobre los recursos naturales de Baja California en el siglo XIX", en Lourdes de Ita y Gerardo Sánchez Díaz (coord.), Humboldt y otros viajeros en América Latina, 2006, Morelia, UMSNH, pp. 193-206; y Rodrigo Vega y Ortega, "Los naturalistas mexicanos y los temas ambientales publicados en La Naturaleza (1870-1905)", en Celina Lértora (coord.), Territorio, recursos naturales y ambiente: Hacia una historia comparada, 2012, Buenos Aires, FEPAI, en proceso de edición. 


\section{José Narciso Rovirosa}

Este insigne tabasqueño nació en 1849 en Acumba, una finca rústica propiedad de la familia, cerca de Macuspana, Tabasco. Después de cursar los estudios primarios migró a la ciudad de Campeche para llevar a cabo estudios profesionales en el Instituto Literario del Estado de Campeche, en el cual obtuvo el título de Ingeniero topógrafo. Poco después ejerció el magisterio en cátedras de Historia natural y Dibujo, en el estado de Chiapas, y posteriormente en el Instituto Juárez de Tabasco. ${ }^{7}$

Como muchos jóvenes de su generación, Rovirosa encontró empleo en la administración pública federal, especialmente en la Secretaría de Fomento. Ésta requería de profesionistas de la ciencia que constituyeran un "cuerpo de funcionarios especializados en el ramo", técnicos, especialmente a partir de 1870. Estos cuadros científico-técnicos fueron más sólidos después de la década de $1890 .{ }^{8}$ Así, el tabasqueño trabajó como agente y explorador al servicio de la Secretaría en diferentes regiones de Chiapas y Tabasco. Asimismo, estuvo en contacto con otros naturalistas mexicanos mediante su participación como miembro corresponsal en la Sociedad Mexicana de Historia Natural, donde publicó varios artículos en la revista La Naturaleza, en los cuales se encuentran sus propuestas sobre el potencial económico de la flora y fauna, además de los recursos geográficos de Tabasco. Además, fue miembro de la Sociedad Científica "Antonio Alzate", la Sociedad Mexicana de Geografía y Estadística y la Sociedad Agrícola Mexicana.

Gracias al apoyo de la Secretaría de Fomento, Rovirosa realizó varias exploraciones naturalistas por el sur de México con la finalidad de conocer e inventariar los recursos naturales y la distribución geográfica de las especies endémicas. "Algunos de sus viajes tuvieron una misión específica, como herborizar una especie determinada, registrar algún dato sobre las condiciones ambientales o recolectar plantas junto con sus

${ }^{7}$ Rafael Rodríguez, “José N. Rovirosa, fitogeógrafo del linde Tabasco-Chiapas: último tercio del siglo XIX", en Enrique Beltrán (ed.), Memorias del Primer Congreso Mexicano de Historia de la Ciencia y de la Tecnología, 1989, México, Sмнсут, p. 736.

${ }^{8}$ María Cecilia Zuleta, "La Secretaría de Fomento y el fomento agrícola en México, 1876-1910: la invención de una agricultura próspera que no fue", Mundo agrario. Revista de Estudios Rurales, 2000, vol. I, núm. 1, p. 4. 
alumnos del Instituto Juárez". ${ }^{9}$ Rovirosa también participó en la vida política estatal como primer regidor del Ayuntamiento de San Juan Bautista (1890 y 1891), diputado por Tabasco (1892-1896) y encargado de la oficina de Fomento regional (1894-1901). ${ }^{10}$

Los escritos de José Narciso Rovirosa tienen como contexto las últimas décadas del siglo XIX, cuando México tuvo un amplio desarrollo material y científico bajo el gobierno de Porfirio Díaz. En esos años, la economía nacional de autoconsumo se transformó en otra de tipo mercantil-capitalista gracias a la amplia construcción de vías férreas y la mejora en los caminos que comunicaron las diversas regiones del país entre sí y con el exterior. Asimismo, se privilegió la exportación de materias primas rumbo a Europa y Estados Unidos. Para la explotación de la naturaleza mexicana fue necesaria la introducción a gran escala de capitales extranjeros, junto con los nacionales, para desarrollar la industria.

Los reconocimientos científicos de Rovirosa estuvieron enmarcados en las acciones gubernamentales que tuvieron como objetivo revertir el atraso estructural que afectaba a la economía al explotar intensivamente los recursos naturales (minería, agricultura y ganadería), pues entre 1821 y 1870 la guerra civil y la inestabilidad política habían impedido el anhelado progreso material. ${ }^{11}$

Particularmente, en el centro y sur de México a partir de la década de 1870 la economía se expandió en términos de agricultura comercial mediante los cultivos de exportación y de utilidad industrial (café, tabaco, henequén, azúcar, algodón, hule, guayule y maguey), al punto que "entre 1870 y 1910 la exportación de productos agropecuarios se incrementó desde un porcentaje inferior al 20 a otro superior al 37\% sobre el total de exportaciones", mientras que las exportaciones mineras disminuyeron un $20 \%$ en el mismo periodo. ${ }^{12}$

Además del intenso cultivo de plantas comerciales, el gobierno federal alentó la exportación de maderas finas a gran escala desde 1880,

${ }^{9}$ Graciela Zamudio, "La botánica y los botánicos al finalizar el siglo XIX mexicano", en Luz Fernanda Azuela y María Luisa Rodríguez-Sala (ed.), Estudios históricos sobre la construcción social de la ciencia en América Latina, 2012, México, UNAM, p. 113.

${ }^{10}$ Rodríguez, op. cit., p. 736.

${ }^{11}$ Zuleta, op. cit., p. 2.

${ }^{12}$ Ibid., p. 3. 
cuando se inició un proceso de liberalización de terrenos ubicados en las "improductivas" selvas, además de propiciar su colonización, ya fuera con habitantes nacionales o extranjeros interesados en dedicarse a la silvicultura. Para ello, se pusieron en práctica nuevas leyes que facilitaran la enajenación de terrenos baldíos y, por extensión, fomentaran la explotación forestal. ${ }^{13}$ Todo ello culminó en la ley de 1894, que estableció la posibilidad de cortar la madera fina de los bosques vírgenes "al celebrar contratos de arrendamiento, aparcería u otros, sin transferir dominio de los terrenos". Conjuntamente, la ley dio pie al "Reglamento para la explotación de los bosques y terrenos baldíos y nacionales" que permitió que los monteros deslindaran totalmente las áreas madereras que tenían arrendadas. ${ }^{14}$

Gracias a esta ley, los bosques de Chiapas, Veracruz, Tabasco, Campeche y Yucatán proveyeron como nunca antes de caoba y cedro al mercado mundial, que a su vez enriquecieron al erario. Igualmente, tanto la ley como el reglamento permitieron el establecimiento de compañías agrícolas de capital mexicano, extranjero y mixto que deslindaron las selvas para fundar cientos de plantaciones dedicadas al cultivo de productos tropicales de exportación (frutas, hule, cacao, café, azúcar y tabaco). ${ }^{15}$

En Tabasco, la explotación de la naturaleza se basó en los productos agrícolas, ganaderos y silvícolas, que proporcionaron recursos fiscales para la entidad. Para ello, desde la década de 1870 los naturalistas buscaron soluciones a las necesidades locales de incrementar la explotación de los recursos mediante su estudio científico. La obra científica sobre Tabasco se encuentra publicada en revistas académicas, informes gubernamentales, monografía sobre la flora y fauna, memorias de gobierno, folletos, libros y discursos. En todo ello contribuyó ampliamente José Narciso Rovirosa.

${ }^{13}$ Héctor Zarauz, "Explotación maderera en el sur de Veracruz en el siglo XIX", en Mario Trujillo y José Contreras (ed.), Formación empresarial, fomento industrial y compañias agrícolas en el México del siglo XIX, 2003, México, CIESAS, p. 286.

${ }^{14}$ Ibid., p. 287.

${ }^{15}$ Claudio Vadillo, "Extracción y comercialización de maderas y chicle en la región de Laguna de Términos, Campeche, siglo XIX", en Mario Trujillo y José Contreras (ed.), Formación empresarial, fomento industrial y compañias agrícolas en el México del siglo XIX, 2003, México, CIESAS, p. 310. 
También al final del siglo XIX se inició la compra de terrenos susceptibles de explotación petrolera en Tamaulipas, San Luis Potosí, Veracruz, Tabasco, Campeche y Chiapas. Esto se reforzó cuando el 4 de julio de 1892 se puso en vigor la nueva ley minera que intentó atraer capital extranjero para la explotación de combustibles minerales. Más tarde, el 24 de diciembre de 1901, se promulgó la primera ley petrolera que determinó "que la empresa concesionaria [tenía] el derecho de expropiar cuando lo requiera, previa indemnización, los terrenos particulares para establecer oficinas o instalar máquinas". ${ }^{16}$ A partir de entonces, varias empresas iniciaron las exploraciones petrolíferas en todo el Golfo de México, lo que trajo consigo el deterioro ambiental de la zona, especialmente en Tabasco. Algunas de estas empresas fueron Waters Pierce, Standard Oil, Texas Mexican, Gulf Refining, Texas Mexican Fuel, Penn Mexican Fuel, Sinclair Sothern Oil \& Transport, Mexican Eagle Company, Mexican Petroleum Company, Mexican Fuel Company, London Oil Trust y S. Pearson \& Son, L.T.D.

\section{Los estudios naturalistas}

En los escritos del naturalista tabasqueño se encuentran datos interesantes para comprender la manera en que la naturaleza regional fue inventariada y los motivos para ello, especialmente la reiterada mención de Rovirosa sobre la incompleta exploración científica de la región y la escaso estudio de la flora local, "por lo que aún no se contaba con un listado completo de sus especies", sobre todo las de utilidad económica. ${ }^{17}$ La confianza en la ciencia del ingeniero se vislumbra cuando afirma en el "Informe [...] sobre el estado de la agricultura en Macuspana, Tabasco" (1880) que:

la agricultura en esta localidad [estaba] en superlativo grado atrasada por las causas que someramente indicaré y que son la siguientes: primera, porque se [cultivaba] la tierra de la misma e idéntica manera

${ }^{16}$ María del Carmen Collado, "El régimen porfirista y la privatización del subsuelo petrolero", Secuencia, 1987, núm. 8, p. 59.

${ }^{17}$ Zamudio, op. cit., p. 114. 
que [hacía] 300 años, no pudiendo decirse que [estuviera] próxima a recibir el poderoso impulso de la ciencia [...] aplicada a todo aquello que el hombre conoce y por medio de lo que camina más y más cada día que [transcurría] en el camino del progreso humano. ${ }^{18}$

Esta causa sintetiza el pensamiento de Rovirosa y de muchos naturalistas mexicanos finiseculares al afirmar que la falta de cientifización de las actividades agropecuarias era la base del atraso económico nacional y regional. Una vez que las ciencias, especialmente la Geografía y la Historia natural, se vincularan con la economía, se pondrían los cimientos para el "progreso" material. En este sentido, otro de los escritos en que se aborda la urgencia de apoyar los estudios científicos sobre las especies vegetales regionales para comercializarlas en el extranjero es el "Discurso [...] al inaugurarse la primera exposición regional tabasqueña de plantas, flores y frutas" (1889), que tuvo como origen la celebración de una de las populares ferias comerciales del porfiriato. En el discurso se aprecia la confianza de Rovirosa en la unión entre explotación de la naturaleza y el progreso material, pues para él las exposiciones regionales eran parte de un

despertar a una nueva vida de mejoramiento social; de impulsar el desarrollo de nuevas industrias en favor de la producción y de la cultura del Estado [porque] los progresos de la agricultura [echaban] los cimientos sólidos del aumento de la población [...] y de ella [dependía] la salud y la longevidad de los hombres. ${ }^{19}$

Bajo estas palabras, Rovirosa apoyó los proyectos gubernamentales de transformar las selvas de Tabasco, que eran valoradas como tierras sin beneficio e improductivas, para que el suelo fértil se utilizaran "solamente para explotar los productos de exportación [y con esto se] aceleró la devastación de bosques con el fin de habilitar tierras para la economía

${ }^{18}$ José Narciso Rovirosa, "Informe del socio José N. Rovirosa sobre el estado de la agricultura en Macuspana, Tabasco", Boletín de la Sociedad Agrícola Mexicana, 1880, vol. I, p. 172.

${ }^{19}$ José Narciso Rovirosa, "Discurso pronunciado por el señor Ingeniero José N. Rovirosa al inaugurarse la primera exposición regional tabasqueña de plantas, flores y frutas", en Sociedad Mexicana de Historia Natural, Obras científicas de José N. Rovirosa (1887-1910), 1978, México, Sociedad Mexicana de Historia Natural, p. 627. 
agroexportadora". ${ }^{20}$ La feria tabasqueña que tuvo el honor de inaugurar estuvo destinada a atraer compradores de materias primas a gran escala para exportar hacia Europa y Estados Unidos.

En este texto también son patentes las razones para aprovechar los recursos naturales tabasqueños como parte de la noción de "progreso" positivista. ${ }^{21}$ Éstas fueron aquilatadas como base del porvenir regional y del desenvolvimiento de la cultura y la riqueza social. Desde la posición del ingeniero naturalista y de la élite regional, la flora y fauna no debían permanecer ociosas ni ignoradas, sino que era forzoso conocerlas en la totalidad en bien del erario. Así, buena parte de la obra de Rovirosa intentó influir en la opinión pública para fomentar el aprovechamiento del medio ambiente local.

En los escritos del científico tabasqueño se encuentra una idea de naturaleza al servicio del ser humano, mediante la cual se podía alcanzar la felicidad y el progreso social. Rovirosa concibió los recursos naturales como inagotables y, dentro de sus convicciones, estuvo la fe en el progreso, tanto económico, como político, social y científico, además de la necesidad de construir una ciencia nacional vigorosa que proporcionara las herramientas para la explotación de la naturaleza; la importancia de integrar a Tabasco al comercio mundial como exportador de materias primas, y la necesidad de colonizar la entidad a partir del reconocimiento geográfico que facilitara la venta de terrenos baldíos.

En Tabasco en la Exposición de París (1889), Rovirosa enunció las plantas que, bajo su juicio científico, tenían un mercado en el comercio de exportación, como cacao, añil, junco, tabaco, cedro, caoba, orquídeas, caña de azúcar y yuca, pues todas estas especies se cultivaban en la entidad. $^{22} \mathrm{Su}$ intervención en la exposición no fue casual, pues su presencia fue un reconocimiento público a la importancia de las élites

\footnotetext{
${ }^{20}$ Rosa Romo, "Hacia una historia ambiental de Tabasco. Ambiente y sociedad en Tabasco", Anuario de Historia, 2008, vol. III, p. 108.

${ }^{21}$ Véase Luz Fernanda Azuela, "La ciencia positivista en el siglo XIX mexicano", en Rosaura Ruiz, Arturo Argueta y Graciela Zamudio (coord.), Otras armas para la Independencia y la Revolución. Ciencias y humanidades en México, 2010, México, FCE/UNAM/UMSNH/HCH/UAS, pp. 172-88.

${ }^{22}$ José Narciso Rovirosa, Tabasco en la Exposición de Paris, 1889, San Juan Bautista, Tipografía del Gobierno, pp. 14-7.
} 
culturales para el progreso material de Tabasco, además de que su participación era garantía de la calidad de los productos expuestos.

Otro tema que se encuentra en el mismo folleto es la deforestación. Al respecto, el tabasqueño expresó que "el papel que [estaban] llamados a desempeñar los bosques y selvas, [era la] base del fomento de diversos ramos industriales", sobre todo, las especies medicinales, tintóreas, textiles, alimenticias, de construcción y ebanistería. ${ }^{23}$ En esta concepción capitalista los bosques estaban condenados a desaparecer paulatinamente, como atestiguó el ingeniero al señalar cómo año con año se desmontaban cientos de hectáreas tabasqueñas para sembrar los cultivos comerciales, aunque parecía que la selva improductiva no se acabaría en, al menos, un siglo.

La práctica agrícola tradicional, lejana de la ciencia, recurría al conocido método de "roza, tumba y quema, que [consistía] en reducir a cenizas los despojos de la vegetación y algunas escardas en el curso del año, que [constituían] las labores del cultivador". ${ }^{24}$ Luego llegaba la ganadería a los prados naturales que eran de dos clases: "las sabanas o llanos cubiertos de gramíneas en las tierras elevadas y las playas o playerías formadas por las cuencas lacustres". ${ }^{25}$ Las primeras se conservan para la quema, efectuada en los meses de marzo, abril y mayo. Cuando se dejaba de producir el maíz en los campos, resultado de la tala del bosque, el terreno se cubría de hierbas conocidas como "grama", destinada al forraje vacuno. El juicio de Rovirosa fue negativo sobre esta práctica, ya que empobrecía la fertilidad del suelo. Para remediar la situación, el ingeniero propuso aplicar los modernos métodos de las ciencias agronómicas para ampliar la productividad. Nuevamente la obra del naturalista es un testimonio de los tradicionales métodos agrícolas que aún en nuestros días se le utiliza en el campo.

La publicación del "Calendario botánico de San Bautista y sus alrededores. Año de 1890" puede ser utilizada para conocer de manera detallada la variedad de las localidades de muestreo en la obra de Rovirosa, pues coincide con la caracterización general de las diferentes zonas

${ }^{23}$ Ibid., p. 13.

${ }^{24}$ Ibid., p. 42.

${ }^{25}$ Ibid., p. 45. 
tabasqueñas en: bosques de Atasta, Mayito, Tamulté y Carrizal; los ríos San Sebastián, Tapijuluya, Espejo, Grijalva y Jícaro; las quintas y haciendas como "Jamet", "Marín", "La Colmena" y "Barceló"; las lagunas de la Pólvora, del Negro y de Atasta; y los pantanos de Mayito. ${ }^{26}$ Esto se reforzó en la caracterización florística general del "Bosquejo de la flora tabasqueña" (1897) a partir de las diferentes zonas de la entidad como: lagunas y pantanos, ríos, lomeríos, sabanas, falda de la sierra y litoral marítimo. ${ }^{27}$ Aunque no profundiza en las especies, gracias a esta caracterización territorial el científico determinó aquéllas que podían explotarse en favor de la economía tabasqueña.

El ingeniero tabasqueño también se interesó por la fauna de su terruño. Mediante su obra zoológica es factible conocer las especies que entonces eran cazadas. Por ejemplo, en los “Apuntes para la zoología de Tabasco" (1897) se reconoce la abundancia del mono saraguato o Mycetes villosus, del cual dijo que "sus gritos, [eran] perceptibles a más de dos kilómetros y capaces de infundir terror a quien por primera vez los [escuchaba]" en las selvas vírgenes del Tortuguero y de Bulují, así como en la sierra próxima a Chiapas. ${ }^{28}$ Otra muestra es el manatí o Manatus australis que entonces habitaba los ríos Chilapa, Usumacinta, Grijalva, los Ídolos y Chilapilla; en ellos, los pescadores los acechaban cuando estaban comiendo, "dormidos o en el momento en que [salían] del agua para respirar. Es indudable que aquella pesca [era] la que [ofrecía] mayores atractivos en los ríos de Tabasco", pues se aprovechaba la piel, huesos y carne con fines comerciales. ${ }^{29}$ Los manatíes y los saraguatos formaban parte de la fauna habitual a finales del siglo XIX, que hoy en día resulta difícil de observar.

En cuanto a las aves, el ingeniero Rovirosa dedicó algunos párrafos a las especies de mayor tráfico comercial, por su belleza, exotismo

${ }^{26}$ José Narciso Rovirosa, "Calendario botánico de San Bautista y sus alrededores. Año de 1890. Estudio consagrado á fijar el carácter de la floración en concordancia con las divisiones del tiempo", La Naturaleza, 1897, vol. II, Segunda Serie, p. 115.

${ }^{27}$ José Narciso Rovirosa, "Bosquejo de la flora tabasqueña”, La Naturaleza, 1897, vol. II, Segunda Serie, pp. 439-41.

${ }^{28}$ José Narciso Rovirosa, “Apuntes para la Zoología de Tabasco. Vertebrados observados en el territorio de Macuspana”, La Naturaleza, 1897, vol. II, Segunda Serie, p. 349.

${ }^{29}$ Ibid., pp. 356-8. 
y utilidad. Primero resalta el águila arpía (Thrasaëtus harpya) de la cual actualmente no se encuentran individuos en libertad. De ella mencionó que había observado ejemplares en el puerto de Frontera y en la ciudad de San Juan Bautista (hoy Villahermosa), pero la mayor cantidad estaba en "las selvas primitivas comprendidas entre los ríos Puscatán y Tulijá, es decir, los sitios húmedos situados en la falda de los Andes de Chiapas, regados por varios riachuelos donde la presencia del hombre es rara". ${ }^{30}$ De la guacamaya (Ara macao), especie americana codiciada por su belleza, Rovirosa mantuvo fresco el recuerdo de las mañanas y tardes "en que [se] deleitaba en San Diego o en las soledades del Chilapilla, contemplando el espléndido plumaje rojo, la larga cola y la voz de las guacamayas, cuando batiendo lentamente sus alas cruzaban el aire". ${ }^{31}$ Ambas especies de aves engalanaron por siglos los cielos tabasqueños y de las cuales quedan solamente los estudios científicos de mexicanos y extranjeros. Una fuente similar de la que también se puede echar mano es el Catálogo de animales colectados por J. N. Rovirosa (1887).

Para José Narciso Rovirosa las materias primas susceptibles de exportación debían ser resultado de un arduo examen científico de calidad, rendimiento y utilidades, para que fueran parte de la riqueza generada en la entidad. Ejemplo de ello fue el artículo llamado "El papel de jolocín" (1890), en que el naturalista pidió al entonces gobernador porfirista Simón Sarlat (1839-1906) que tomara en cuenta la voz de los científicos para "abrir en Tabasco nuevas fuentes de prosperidad tomadas al reino vegetal [y] exhibir en la capital de la República" los productos regionales que potencialmente serían comercializados en el mundo entero. ${ }^{32}$ Como se aprecia, los naturalistas estaban interesados en ser tomados en cuenta como actores sociales imprescindibles en el desarrollo económico, pues los estudios que publicaban sobre reconocer, catalogar y estudiar los recursos naturales del medio tabasqueño eran la base para el enriquecimiento del erario y de la sociedad.

${ }^{30}$ Ibid., p. 376.

${ }^{31}$ Ibid., p. 373.

${ }^{32}$ José Narciso Rovirosa, "El papel de jolocín”, en Sociedad Mexicana de Historia Natural, Obras científicas de José N. Rovirosa (1887-1910), 1978, México, Sociedad Mexicana de Historia Natural, p. 204. 
Rovirosa alentó un proyecto particular de explotación del árbol llamado jolocín ${ }^{33}$ que trató del aprovechamiento del tejido cortical de éste en la fabricación del papel. La explotación de dicha especie sólo sería posible al establecer fábricas de papel en Tabasco, pues impulsaría el progreso material de la localidad. ${ }^{34}$ La utilidad de esta especie nativa fue uno de los tantos proyectos que diferentes naturalistas del porfiriato idearon para que México no sólo fuera considerado como exportador de materias primas, sino como un país que debía industrializarse, con la finalidad de aprovechar en la misma región las riquezas del suelo mexicano.

El naturalista tabasqueño, con este tipo de escritos, influyó en la opinión tabasqueña al dar cuenta de sus ideas y creencias con respecto a la explotación capitalista de los recursos naturales, de la fe positivista en el progreso social y de la necesidad de impulsar el desarrollo científico y tecnológico como base de la prosperidad tabasqueña. Asimismo, la obra de Rovirosa permite al historiador ambiental profundizar en las especies más representativas de los distintos ecosistemas existentes en Tabasco al inicio de la explotación de la región y conocer sus consecuencias mediante la comparación con investigaciones actuales.

\section{Los estudios geográficos}

En los escritos científicos de José Narcivo Rovirosa también tuvieron cabida los aspectos geográficos de Tabasco, los cuales al ser estudiados, daban pautas para reforzar los proyectos de explotación de la naturaleza regional. El primer tópico fue el climático, como se aprecia en "Apuntes para el estudio de la meteorología del sur de México" (1898). ${ }^{35}$ El escrito tuvo como propósito no sólo "llegar a conclusiones

${ }^{33}$ El jolocín, cuyo nombre científico es Heliocarpus appendiculatus, pertenece a la familia Tiliacieae. Es un árbol nativo del sureste de México y Centroamérica.

${ }^{34}$ Ibid., pp. 204-205.

${ }^{35}$ Sobre el desarrollo de la Meteorología mexicana véase Luz Fernanda Azuela, "La institucionalización de la meteorología en México a finales del siglo XIX", en María Luisa Rodríguez Sala y Omar Moncada (coord.), La cultura científico-tecnológica en México: nuevos materiales multidisciplinarios, 199, México, UNAM, pp. 99-106. 
especulativas, sino trazar un bosquejo de los fenómenos y apuntar las causas que en [su] humilde concepto [debían] considerarse como ocasionales de los movimientos atmosféricos". ${ }^{36}$ Los datos acopiados fueron registrados diariamente en zonas de Campeche, Tabasco y Chiapas, tanto en costas como en llanos y montañas.

De esta manera, Rovirosa llegó a conclusiones preliminares sobre el origen de los fenómenos climatológicos dentro del "armonioso conjunto de la naturaleza”. Asimismo, consignó cifras sobre la precipitación media anual en lugares como Orizaba, Córdoba, Oaxaca, San Juan Bautista, Tlacotalpan, entre otras localidades del sureste mexicano, mismas que pueden compararse con las mediciones actuales para conocer los cambios que se han llevado a cabo en este rubro ambiental. ${ }^{37}$

Acerca de los fenómenos meteorológicos conocidos como "nortes", Rovirosa escribió en Hidrografía del sudeste de México y su relación con los vientos y las lluvias que dicho fenómeno atmosférico soplaba con intervalos en septiembre a octubre, y a veces entre diciembre y marzo, siendo "su duración era de muchos días en épocas pasadas". ${ }^{38}$ Pero, según hizo notar en la obra Reseña Geográfica y Estadística del Estado de Tabasco (1890), se operó un cambio notable en el régimen de estos fenómenos que merecían mayores estudios, pues se desconocía la causa. ${ }^{39}$

El ingeniero Rovirosa expresó sobre las lluvias que parecía "haberse operado de algunos años a la fecha un cambio notable en el sentido de su disminución, fenómeno interesante de cuya marcha [se debía] deplorar [que] no [hubieran] quedado datos precisos". ${ }^{40}$ Como causa de esto señaló la tala de bosques que aumentaba día a por el cultivo de nuevos campos y el crecimiento de las industrias forestales. Tanto los nortes como las lluvias periódicas eran parte de los elementos que conforman la par-

${ }^{36}$ José Narciso Rovirosa, “Apuntes para el estudio de la meteorología del sur de México”, en Sociedad Mexicana de Historia Natural, Obras cientificas de José N. Rovirosa (1887-1910), 1978, México, Sociedad Mexicana de Historia Natural, p. 327.

${ }^{37}$ Ibid., p. 329.

${ }^{38}$ José Narciso Rovirosa, Hidrografía del sudeste de México y su relación con los vientos y las lluvias, 1945, Villahermosa, Gobierno Constitucional de Tabasco, p. 43.

${ }^{39}$ José Narciso Rovirosa, Reseña Geográfica y Estadística del Estado de Tabasco, 1890, San Juan Bautista, Tip. "El Gran Libro", p. 8.

${ }^{40}$ Rovirosa, op. cit., Tabasco, p. 7. 
ticularidad de la región tabasqueña. Mediante los datos y descripciones consignados en el escrito es posible comprender los cambios meteorológicos que han existido entre el final del siglo XIX y la actualidad.

De la crecida de los ríos, el ingeniero también realizó estudios, pues dejó testimonio sobre el nivel más alto de las aguas fluviales que correspondía a los meses de septiembre y octubre. En dichos meses, casi toda la llanura de formación aluvial era invadida por las aguas, por lo que Tabasco se convertía en un inmenso lago sembrado de islas. ${ }^{41}$ El naturalista estuvo convencido de que los estudios científicos sobre la hidrografía sería la base del progreso económico tabasqueño, al favorecer el desarrollo de la agricultura y del comercio mediante la navegación interior de la marina mercante. En este sentido, Rovirosa percibió la estrecha relación entre la población rural y los ríos, lo que ahora es entendido como "la historia de las relaciones que los hombres establecieron con los elementos naturales". ${ }^{42}$

Con este objeto, el ingeniero tabasqueño describió los principales ríos del sureste mexicano, junto con sus afluentes, las cuencas que los formaban, los poblados por los que pasaban y las posiciones geográficas. Algunos ríos que describió en Hidrografía del sudeste de México fueron Tulijá, Jataté, Usumacinta, Michol y Coatzacoalcos. ${ }^{43}$ En este ámbito, un ejemplo de la interacción entre sociedad y medio ambiente lo encontramos en Ensayo histórico sobre el rio Grijalva en que abordó los cambios que se habían suscitado en éste desde la época virreinal. Por ejemplo, ante los ataques de piratas en Tabasco, las poblaciones cercanas al

río de Dos Bocas (Río Seco), la vía fluvial por donde más se facilitaba la entrada de las naves piráticas, construyeron en varios puntos del río, y muy especialmente a inmediaciones de la actual villa de Cárdenas, unas estacadas y diques de tierra y troncos de árboles [para] desviar las corrientes y oponer un obstáculo a las fuerzas invasoras. ${ }^{44}$

${ }^{41}$ Ibid., p. 7.

${ }^{42}$ Gilmar Arruda, “Historia de ríos ¿Historia ambiental?”, Signos Históricos, 2006, núm. 16, p. 20.

${ }^{43}$ Rovirosa, op. cit., Hidrografía, pp. 9-12.

${ }^{44}$ Ibid., pp. 26-7. 
Ello trajo como consecuencia que el río se abriera en dos nuevos cauces a través de las tierras bajas, uno de los cuales se unió al río Limón, y el otro corrió hacia el Mezcalapa. ${ }^{45}$ Con el paso de los años el río principal fue perdiendo el nivel del agua, lo que favoreció a los asentamientos de españoles. Además, las primitivas plantaciones "se convirtieron en florecientes haciendas y se fundaron nuevos establecimientos agrícolas en donde antes no los había". ${ }^{46}$ Las antiguas tierras del río eran tan fecundas para la agricultura que, a principios del siglo XIX, se establecieron varias haciendas en el antiguo cauce y en las islas resultantes, como fueron "San Cayetano" y "Guanajay", y poblaciones como Paraíso. En esta última se observaba "que todas las construcciones se [habían] practicado sobre el lecho, aun en lo que fue eje de las antiguas corrientes". ${ }^{47}$ Durante los años en que Rovirosa se desarrolló profesionalmente se intensificó el proceso de modificación hidrográfico iniciado en tiempos coloniales, por medio de hacendados, rancheros, campesinos y colonos que fueron ganando espacio a los ríos para incrementar la explotación de los recursos naturales regionales. ${ }^{48}$

El naturalista también estuvo interesado en explicar científicamente la crecida de los ríos, por lo que analizó factores como vientos, corrientes de aire, orografía e intensidad de los rayos solares. De todo esto escribió:

Tócame ahora hacer ver que en las crecientes y las inundaciones, su consecuencia inmediata, están sujetas en Tabasco a una ley de periodicidad. Para no remontarme a épocas muy lejanas, citaré las inundaciones extraordinarias de 1868,1879, 1888, de triste recordación por sus desastrosos efectos, las cuales [pusieron] de manifiesto que esos fenómenos se [venían] produciendo con intervalos de $10 \mathrm{u} 11$ once años. ${ }^{49}$

${ }^{45}$ José Narciso Rovirosa, Ensayo histórico sobre el rio Grijalva. Examen crítico de las obras antiguas y modernas que tratan de los descubrimientos de Juan de Grijalva y de los primeros establecimientos de los conquistadores españoles en Tabasco, 1946, Villahermosa, Gobierno Constitucional de Tabasco, pp. 11-2.

${ }^{46}$ Ibid., pp. 13-4.

${ }^{47}$ Ibid., p. 14.

${ }^{48}$ Sobre el tema véase Rodolfo Uribe, "La alquimia del desarrollo sobre el trópico: el caso de Tabasco (uso de la articulación compleja de temporalidades procesales para explicar la problemática socioambiental de la llanura costera del Golfo de México)", Anuario de Historia, 2005, vol. III, p. 20.

${ }^{49}$ Rovirosa, op. cit., Hidrografia, p. 47. 
Rovirosa, mediante la observación y la sistematización de los datos recabados durante varios lustros, intentó establecer una periodicidad de las inundaciones regionales, ya que la ciencia positiva en la que estaba imbuido tenía como meta el establecimiento de leyes de la naturaleza. Éstas debían tener una aplicación práctica para la sociedad, en este caso, la predicción del desbordamiento de los ríos que afectaban cada diez $u$ once años a la región.

José Narciso Rovirosa enfatizó en "Productos vegetales en las palizadas del Grijalva y sus afluentes" (1890) que era imprescindible destinar recursos del erario a recabar datos "para fijar con exactitud la extensión superficial de las comarcas cuyas aguas vienen a reunirse en el cauce común del Grijalva, pero los elementos cartográficos que tenemos a la vista nos dan aproximadamente un área de 7,127 kilómetros cuadrados". ${ }^{50}$ Esta información era necesaria para los procesos de deslinde de terrenos y colonización de Tabasco durante el final del siglo XIX, que se ven reflejados en el Informe rendido a la Secretaría de Fomento... (1897).

En dicho informe, se narró la disputa de un terreno llamado "la Isla" en la jurisdicción de Teapa, con ayuda de la localización geográfica y el estudio de los ríos cercanos, además del uso de un sintético análisis de Geografía histórica que versa sobre las modificaciones a lo largo del tiempo de dichos ríos, como referencia de los títulos de propiedad coloniales, y los cambios de dueño. Como los títulos de propiedad coloniales tenían como referencia el curso del río, se suscitaron problemas un siglo después sobre si eran terrenos baldíos o si tenían propietario. ${ }^{51}$ Cabe señalar que este informe tuvo un anexo titulado $\mathrm{Ca}$ tálogo de maderas de construcción y ebanistería que producen los bosques de Maluco, la Sandía, Alcalde-Mayor y Playas de Patricio, formando en la Agencia de la Secretaría de Fomento en el ramo de terrenos baldios en Tabasco, para acompañar el informe que antecede (1897) en

${ }^{50}$ José Narciso Rovirosa, "Productos vegetales en las palizadas del Grijalva y sus afluentes", La Naturaleza, 1890, vol. I, Segunda Serie, p. 408.

${ }^{51}$ José Narciso Rovirosa, Informe rendido a la Secretaría de Fomento por el agente de la misma en el ramo de terrenos baldios en Tabasco, Ingeniero D. José N. Rovirosa sobre los títulos de la Merced Real de la Isla, 1897, San Juan Bautista, Tipografía y Encuadernación de M. Gabucio M., pp. 5-8. 
que se enfatizó el recurso florístico de la zona susceptible de explotación comercial. ${ }^{52}$

En cuanto a la colonización de Tabasco, el naturalista escribió en Tabasco en la Exposición de Paris la necesidad de promocionar las ventajas geográficas para colonizar e invertir capital en la entidad. Uno de los foros para ello fue la Exposición Universal de París de 1889, en la cual participó una delegación tabasqueña. ${ }^{53}$ Los naturalistas, como Rovirosa, en varias ocasiones se sumaron a proyectos del gobierno de Porfirio Díaz que tuvieron como objeto la promoción de las ventajas de emigrar hacia México. Para ello, fue necesario exponer a los interesados las bondades de radicar en Tabasco mediante la exhibición pública de mapas, imágenes, estadísticas y especímenes naturales que convencieran a los dudosos de mudarse al sureste mexicano.

En este sentido, Rovirosa en el Informe dirigido a la Secretaría de Fomento en 22 de Julio de 1884 ... aportó datos regionales para la formación del gran proyecto sobre la geografía médica de la República Mexicana que estaba acorde con "los ardientes deseos que el Poder Ejecutivo [abrigaba] de estudiar todas las cuestiones que directa e indirectamente se [relacionaban] con la inmigración, elemento indispensable para el aumento de la población y la explotación de nuestro rico suelo". ${ }^{54}$

Aunque la Historia natural fue la disciplina preponderante en la obra de Rovirosa, la Geografía fue una de las ciencias de mayor utilidad a la hora de elaborar sus estudios científicos, ya que las características orográficas, hidrográficas y climatológicas de Tabasco eran fundamentales para establecer los recursos naturales susceptibles de explotación económica, aunque para la década de 1890 éstas aún no estaban del todo delineadas.

\footnotetext{
${ }^{52}$ Sobre el tema véase Consuelo Cuevas, "Estudios naturalistas de la Secretaría de Fomento: La Sección de Historia Natural de la Comisión Geográfico-Exploradora de México (1882-1915)", en Celina Lértora (coord.), Geografía e Historia natural: hacia una historia comparada. Estudios a través de Argentina, México, Costa Rica y Paraguay, 2009, Buenos Aires, FEPAI, tomo II, pp. 159-178.

${ }^{53}$ Véase Mauricio Tenorio Trillo, Artilugio de la nación moderna. México en las exposiciones universales, 1880-1930, México, FCE, 1998.

${ }^{54}$ Rovirosa, op. cit., Informe, p. VI.
} 


\section{Consideraciones finales}

Las fuentes de la Historia ambiental son variadas; en este caso, la obra de un científico es un recurso para varios de los tópicos que aborda esta clase de investigaciones históricas. La obra de José Narciso Rovirosa resulta útil para comprender los distintos procesos ambientales de Tabasco y su relación con la sociedad que se desarrolló ahí durante el porfiriato. Asimismo, es un testimonio científico del reconocimiento y del inventario de los seres vivos, de los elementos abióticos y de las prácticas culturales relacionadas con la naturaleza. La obra de este ingeniero, como la de otros científicos, está compuesta por datos cuantitativos y cualitativos. Dentro de los primeros, como se ha visto, se encuentran aquellos referentes a localidades, mediciones, observaciones y rastros físicos; mientras que en los segundos están las apreciaciones paisajísticas, juicios de valor e ideas científicas.

Los estudios del naturalista tabasqueño, que han llegado hasta el presente, tienen una importancia particular en la sociedad actual, como la amenaza o extinción de algunas especies mexicanas, por ejemplo, el águila arpía y el manatí, entre muchas otras. De la misma manera, se encuentran las modificaciones que los tabasqueños han hecho en el medio ambiente a lo largo del tiempo, como los nuevos cursos de los ríos, la desecación de los pantanos o la deforestación. En este último ejemplo también es posible comprender la forma en que se llevó a cabo el aprovechamiento de los recursos naturales según el modo tradicional (de pescadores y agricultores) o capitalista (de empresarios e inversionistas).

Acerca del desarrollo social y económico del porfiriato, Rovirosa dejó documentación científica de gran utilidad para rastrear la apertura tabasqueña hacia los mercados mundiales que demandaban materias primas, pues esta entidad se convirtió al final del siglo XIX en gran exportador de plantas y animales.

La degradación ambiental de la región puede ser explicada de mejor manera a partir de las fuentes científicas, pues no sólo exponen las especies botánicas y zoológicas que habitaban ahí y que ahora se encuentran en peligro de extinción o ya han desaparecido, sino que también permiten reconocer el valor económico que muchas de ellas 
tuvieron, lo que explica su disminución poblacional. Asimismo, se advierte que parte de la degradación del ambiente fue consecuencia del afán naturalista de la época por conocer la riqueza natural de la región para insertarla en el desarrollo económico nacional y mundial, a manera de sustento del progreso tabasqueño.

Rovirosa, como otros naturalistas, fue un delineador de los recursos naturales mexicanos con el objetivo de aprovecharlos económicamente. Durante el porfiriato, estos hombres expresaron la necesidad de ser valorados como cuerpo consultivo, puesto que resultaban los más preparados para estudiar la flora y fauna, y para aconsejar sobre su aprovechamiento. A diferencia del presente, puede resultar contradictorio para algunos científicos que un hombre que dedicó su vida al estudio de la naturaleza haya sido uno de los más interesados en propiciar su transformación acelerada y que no alzara la voz para conservarla prístina. Y es que, a diferencia de hoy en día, la Historia natural estaba interesada en la utilidad de las diferentes especies. Era una concepción de naturaleza al servicio del hombre, que no es la nuestra. Aunque Rovirosa, como otros, tampoco alentaba una explotación irracional de la naturaleza, sino una manera científica, racional, ordenada y pragmática.

Los estudios naturalistas sobre los recursos susceptibles de explotación, como plantas y animales, además de los geográficos, como vías de comunicación, ya fueran ríos o puertos, estuvieron de acuerdo con las necesidades de desarrollo económico, por medio del capitalismo. Resultaba necesario crear una base social fundada en pequeños propietarios que trabajaran la tierra tras su deslinde. Estos colonos, mexicanos o extranjeros, eran vistos como los motores de la prosperidad tabasqueña en el naciente siglo XX.

Un estudio más amplio de la historia ambiental de Tabasco debe constituirse mediante varios tipos de fuentes distintas. Las fuentes científicas pueden apoyarse en otras, como testimonios de vida cotidiana, aquellos generados por el gobierno, los de carácter económico y culturales. La de tipo científico podría ser exhaustiva en cuanto a un solo hombre, o cruzar la información de varios científicos en una época o a lo largo de diferentes décadas. 
CITAM Derechos Reservados.

La reproducción total o parcial de este artículo se podrá hacer si el ITAM otorga la autorización previamente por escrito. 